\title{
Atividade antimicrobiana e indutora de fitoalexinas do hidrolato de carqueja [Baccharis trimera (Less.) DC.]
}

MOURA, G.S. ${ }^{1 ;}$ FRANZENER, G. ${ }^{2}$; STANGARLIN, J.R. ${ }^{{ }^{*}}$; SCHWAN-ESTRADA, K.R.F. ${ }^{1}$

Departamento de Agronomia, Universidade Estadual de Maringá-UEM, Av. Colombo, 5790, CEP 87.020-200, Maringá-PR; '2Universidade Federal da Fronteira Sul-UFFS, BR 158, km 405, CEP 85301-970, Laranjeiras do Sul-PR; ' ${ }^{C}$ Centro de Ciências Agrárias, Universidade Estadual do Oeste do Paraná-UNIOESTE, Rua Pernambuco, 1777, CEP 85960-000 - Marechal Cândido Rondon, PR. *jrstangarlin@pq.cnpq.br.

RESUMO: Hidrolato é o líquido resultante da extração de óleo essencial de plantas aromáticas por arraste a vapor apresentando em sua composição importantes metabólitos do vegetal de origem. O objetivo deste trabalho foi avaliar a atividade indutora de fitoalexinas, bem como as propriedades antifúngica e antibacteriana do hidrolato de carqueja (Baccharis trimera). Foram testadas as concentrações de 1, 10, 25, 50, 75 e 100\%. A atividade indutora de fitoalexinas foi avaliada em mesocótilos estiolados de sorgo e em cotilédones de soja. A atividade antifúngica foi avaliada sobre a germinação de esporos de Pseudocercospora vitis, Cercospora kaki e Hemileia vastatrix. A atividade antibacteriana foi avaliada sobre a multiplicação de Xanthomonas campestris pv. passiflorae, Erwinia carotovora e Bacilllus subtilis. O hidrolato não induziu a produção de fitoalexinas em soja, mas promoveu esta atividade em sorgo a partir da concentração de $50 \%$. Atividade antibacteriana ocorreu para os três isolados a partir da concentração de $75 \%$, com inibição de até $87,9 \%$ sobre $B$. subtilis. O hidrolato não mostrou atividade antifúngica.

Palavras-chave: antifúngico, antibacteriano, gliceolina, deoxiantocianidinas.

ABSTRACT: Antimicrobial activity and phytoalexin induction of Baccharis trimera (Less.) DC. hydrolate. Hydrolate is a product resulting from the extraction of a plant essential oil using steam distillation, which presents major metabolites of such plants in its composition. The objective of this work was to evaluate the phytoalexin induction and the antifungal and antibacterial activities of the Baccharis trimera hydrolate, in the concentrations of 1, 10, 25, 50,75 and $100 \%$. Phytoalexin induction was evaluated in etiolated sorghum mesocotyl and in soybean cotyledons. The antifungal activity was evaluated on the spore germination of Pseudocercospora vitis, Cercospora kaki and Hemileia vastatrix, while the antibacterial activity was evaluate on the Xanthomonas campestris pv. passiflorae, Erwinia carotovora and Bacillus subtilis multiplication. The hydrolate did not induce the phytoalexin synthesis in soybean, but it provided activity in sorghum in the concentration of $50 \%$ and above. Antibacterial activity occurred for the three isolates tested at the concentrations of 75 and $100 \%$, with inhibition up to $87.9 \%$ for $B$. subtilis. The hydrolate showed no antifungal activity.

Keywords: antifungal, antibacterial, glyceollin, deoxyanthocyanidins.

\section{INTRODUÇÃO}

A utilização indiscriminada de agrotóxicos no controle de doenças de plantas tem ocasionado problemas de contaminação ambiental, intoxicação humana, e seleção de populações de patógenos resistentes a esses produtos químicos (Ghini \& Kimati, 2000). Assim, práticas alternativas para o controle de doenças menos prejudiciais ao ambiente, vêm obtendo cada vez mais importância.

A diversidade de substâncias ativas em plantas medicinais têm motivado estudos na área farmacêutica (Rios \& Recio, 2005), bem como o desenvolvimento de pesquisas envolvendo extratos e óleos essenciais, tendo em vista o controle de doenças em plantas, com resultados promissores (Schwan-Estrada \& Stangarlin, 2005).

Existem relatos da atividade direta de extratos e óleos essenciais de plantas sobre fitopatógenos (Fiori et al., 2000; Kagale et al., 2004; 
Motoyama et al., 2003), tais como fungos, bactérias, vírus e nematóides, ou indireta, ativando mecanismos de defesa das plantas aos patógenos (Franzener et al., 2003; Moreira, 2003; Stangarlin et al., 2008). Entre as respostas de defesa vegetal destacamse as fitoalexinas, compostos antimicrobianos de baixa massa molecular sintetizados pelas plantas em resposta a ação de agentes bióticos ou abióticos. Compostos/moléculas capazes de induzir resistência em plantas são denominados de eliciadores ou elicitores (Bonaldo et al., 2004). Mesocótilos estiolados de sorgo e cotilédones de soja são considerados como excelentes ferramentas em estudos para verificação da ação eliciadora de moléculas de origem biótica ou abiótica (Cavalcanti et al., 2005).

Embora a maioria dos estudos com produtos alternativos para controle de fitopatógenos tenha sido realizado com extratos ou óleos essenciais, outros métodos de extração ou compostos podem ainda ser utilizados, como o hidrolato, sendo este 0 líquido resultante do processo de extração de óleo essencial por arraste a vapor, o qual apresenta geralmente compostos voláteis hidrossolúveis como ácidos, aldeídos e aminas (Lavabre, 1993), em quantidades que podem variar desde $0,05 \mathrm{a}$ $0,20 \mathrm{~g}$ de óleo essencial por litro. Atualmente, os hidrolatos têm sido utilizados para preparação de xaropes e em cosmetologia (Teske \& Trentini, 1997). Embora possam conter importantes princípios ativos são escassas as informações do seu emprego no controle de doenças em plantas. Lozano et al. (2000) relatam a inibição no desenvolvimento dos fungos fitopatogênicos Botrytis alli e Sclerotium cepivorum por hidrolatos de alho (Allium sativum) e cebola (Allium cepivorum) (Lozano et al., 2000). Franzener et al. (2007) relataram ainda o potencial antifúngico, antibacteriano e indutor de fitoalexinas por hidrolatos de Helietta apiculata (canela-de-veado), Conyza canadensis (buva) e Cymbopogon nardus.

Baccharis trimera (Less.) DC., popularmente conhecida como carqueja, tem sido amplamente utilizada no Brasil na medicina popular (Lorenzi \& Matos, 2002). O decocto desta planta já mostrou elevado efeito bactericida contra Staphylococcus aureus e Streptococcus uberis (Avancini et al., 2000; Oliveira et al., 2005). Também o óleo essencial e o extrato bruto apresentou efeito fungitóxico contra Rhizoctonia solani, Sclerotium rolfsii, Alternaria alternata, Phytophthora sp. e Colletotrichum graminicola (Stangarlin et al., 1999). Apesar disso, não se dispõe de informações sobre a atividade do hidrolato desta planta.

Assim, o objetivo do presente trabalho foi avaliar o efeito antifúngico e antibacteriano do hidrolato de carqueja sobre fitopatógenos, bem como a atividade indutora de fitoalexinas em mesocótilos de sorgo e cotilédones de soja como indicativo de seu potencial para o controle alternativo de doenças de plantas.

\section{MATERIAL E MÉTODOS}

Os experimentos foram realizados no Laboratório de Fitopatologia da Universidade Estadual do Oeste do Paraná - Unioeste, Câmpus de Marechal Cândido Rondon/PR, sendo os ensaios conduzidos em delineamento experimental inteiramente casualizado, com quatro repetições.

\section{Obtenção do hidrolato}

O hidrolato de carqueja foi obtido por sistema de extração de óleo essencial por arraste a vapor, em aparelho tipo Clevenger, na Estação Experimental Antônio Carlos dos Santos Pessoa da Unioeste. Foram empregadas as proporções de $3 \mathrm{~kg}$ de folhas frescas para obtenção de $2 \mathrm{~L}$ de hidrolato. Este foi separado através de decantação e mantido em garrafa plástica (pet) envolvida em papel alumínio e armazenado a $4{ }^{\circ} \mathrm{C}$ até seu emprego nos ensaios. Imediatamente antes da utilização nos experimentos, o hidrolato foi esterilizado através da filtragem em membrana Millipore $(0,45$ $\mu \mathrm{m}$ de diâmetro de poro). Foi utilizado o hidrolato nas concentrações de 1, 10, 25, 50, 75 e 100\% obtido pela diluição em água destilada esterilizada (Franzener et al., 2007).

\section{Produção de fitoalexinas em cotilédones de soja}

Sementes de soja (Glycine max L.) do cultivar CD 215 foram desinfestadas em hipoclorito de sódio 1\% (15 min), lavadas em água destilada, semeadas em areia esterilizada e mantidas em casa-de-vegetação. Dez dias após, os cotilédones foram destacados das plântulas, lavados em água destilada, enxugados, e cortados em secção de aproximadamente de $1 \mathrm{~mm}$ de espessura e $6 \mathrm{~mm}$ de diâmetro a partir da superfície inferior. Cinco cotilédones foram pesados e colocados em placa de Petri com papel de filtro umedecido com água destilada estéril. Sobre cada cotilédone foi aplicada uma alíquota de $40 \mu \mathrm{L}$ de cada concentração de hidrolato. As placas foram mantidas a $25^{\circ} \mathrm{C}$ em escuro por 20 horas, e, em seguida, os cotilédones foram transferidos para frascos plásticos contendo $15 \mathrm{~mL}$ de água destilada estéril e agitados por 1 hora para extração da fitoalexina formada. A absorbância foi determinada a $285 \mathrm{~nm}$ (Ziegler \& Pontzen, 1982).

\section{de sorgo}

Produção de fitoalexinas em mesocótilos

Sementes de sorgo [Sorghum bicolor (L.) Moench], cultivar Brandes, foram desinfestadas

Rev. Bras. PI. Med., Campinas, v.16, n.2, supl. I, p.309-315, 2014. 
em hipoclorito de sódio $1 \%$ por 15 min e lavadas em água destilada. Em seguida foram enroladas em folhas de papel de germinação umedecidas e incubadas em escuro a $28{ }^{\circ} \mathrm{C}$ durante quatro dias em câmara de germinação tipo BOD. As plântulas foram expostas sob luz fluorescente por 4 horas para analisar a elongação dos mesocótilos (Nicholson et al., 1988).

Para determinação da produção de fitoalexinas, os mesocótilos foram excisados 0,5 $\mathrm{cm}$ acima do nó escutelar e colocados em tubos para microcentrífuga (volume de $1,5 \mathrm{~mL}$ ) (três mesocótilos/tubo), contendo alíquota de 1,4 mL de cada concentração de hidrolato, sendo em seguida mantidos em câmara úmida, a $25{ }^{\circ} \mathrm{C}$ sob luz fluorescente, durante 60 horas. Após esse período foram retirados dos tubos, secos em papel absorvente, e os $5 \mathrm{~mm}$ basais de cada mesocótilo foram excisados e descartados. A porção superior $(2,5 \mathrm{~cm})$ foi pesada e cortada em pequenos segmentos $(0,5 \mathrm{~cm})$ eacondicionados em tubos para microcentrífuga contendo $1,5 \mathrm{~mL}$ de metanol $80 \%$ acidificado $(0,1 \% \mathrm{HCl}$; v/v) e mantidos em metanol por 96 horas a $4{ }^{\circ} \mathrm{C}$ para extração dos pigmentos. Após, determinou-se a absorbância a $480 \mathrm{~nm}$ (Nicholson et al., 1988). Como testemunhas foram empregados: água destilada esterilizada, solução de Saccharomyces cerevisae (fermento biológico fresco) (20 $\mathrm{mg} \mathrm{mL}^{-1}$ ) para soja e acibenzolar-S-metil (ASM) (50 mg i.a. $\left.\mathrm{L}^{-1}\right)$ para sorgo.

\section{Inibição da multiplicação bacteriana}

$O$ efeito antibacteriano foi avaliado no desenvolvimento das bactérias Xanthomonas campestris pv. campestris, Erwinia carotovora e Bacillus subtilis isoladas de folhas de repolho (Brassica oleraceae var. capitata), frutos de pimentão (Capsicum annuum) e sementes de soja (Glycine max), respectivamente. Estas bactérias foram isoladas e cultivadas em meio ágar nutriente (1000 $\mathrm{mL}$ de água destilada, $5 \mathrm{~g}$ de peptona, 3 $\mathrm{g}$ de extrato de carne e $18 \mathrm{~g}$ de ágar). Tubos de ensaio estéreis (capacidade $10 \mathrm{~mL}$ ) contendo concentrações iguais para meio de cultura / caldo nutriente receberam as concentrações do hidrolato totalizando $5 \mathrm{~mL}$ por tubo. Cada tubo recebeu 100 $\mu \mathrm{L}$ de suspensão bacteriana com $10^{8}$ UFC mL-1 e foram mantidos sob agitação durante 48 horas a $27^{\circ} \mathrm{C}$ quando foi determinada a absorbância a 580 $\mathrm{nm}$. Nesta determinação, cada tratamento teve como amostra de referência (branco) uma repetição sem a bactéria. Constituíram testemunhas: o meio caldo nutriente sem antibiótico, e outra, contendo antibiótico $\left(22,5 \mathrm{mg} \mathrm{L}^{-1}\right.$ de oxitetraciclina $+225 \mathrm{mg}$ $\mathrm{L}^{-1}$ de estreptomicina).

\section{fungos}

Inibição da germinação de esporos de

Conídios de Pseudocercospora vitis, Cercospora kaki e Hemileia vastatrix foram obtidos de infecções naturais em folhas de videira (Vitis sp.), caqui (Diospyros kaki) e café (Coffea arabica), respectivamente. Para extração dos conídios, lesões com abundante esporulação foram destacadas, colocadas em erlenmeyer com água destilada estéril, agitadas a $50 \mathrm{rpm}$ e filtradas em gaze. Uma alíquota de $40 \mu \mathrm{L}$ da suspensão de esporos ( $1 \mathrm{x}$ $10^{4}$ conídios $\mathrm{mL}^{-1}$ ) e outra de $40 \mu \mathrm{L}$ doshidrolatos , foram colocadas em cada um dos poços de placa de microtitulação (Regente et al., 1997). As placas foram incubadas em escuro a $25^{\circ} \mathrm{C}$ por 16 horas quando a germinação de esporos foi paralisada com $20 \mu \mathrm{L}$ de azul de lactofenol. A determinação da porcentagem de germinação foi realizada através da contagem de 100 esporos por parcela em microscópio ótico, tendo sido considerado germinados aqueles esporos cujos tubos germinativos apresentavam tamanho maior ou igual ao menor diâmetro do esporo. Também foram mensurados 10 tubos germinativos por parcela para determinação do tamanho médio dos mesmos. Neste bioensaio utilizou-se como testemunha: água destilada esterilizada e o fungicida azoxystrobin $\left(0,08\right.$ g i.a. $\left.L^{-1}\right)$.

\section{RESULTADOS E DISCUSSÃO}

Produção de fitoalexinas em soja e sorgo Os resultados indicam que não houve acúmulo significativo de fitoalexinas em cotilédones de soja pelo hidrolato de $B$. trimera, independentemente da concentração utilizada.

O único tratamento que promoveu aumento na síntese de fitoalexinas, conforme esperado, foi a solução de $S$. cerevisiae, cujo incremento foi de 8,5 vezes em relação à testemunha água.

Resultados semelhantes foram obtidos em mesocótilos de sorgo. Maior incremento na síntese de fitoalexinas foi obtido pela testemunha ou controle positivo ASM, que foi 10 vezes maior que na testemunha ou controle negativo, água (Figura 1). Em sorgo, porém, o hidrolato de $B$. trimera promoveu significativo acúmulo de fitoalexinas a partir da concentração de $50 \%$ na qual houve produção de fitoalexinas 3,3 vezes superior à testemunha água.

A baixa atividade do hidrolato observada nos ensaios deve-se, possivelmente, à baixa concentração de compostos com propriedades elicitoras. No entanto, esta atividade em sorgo não deve ser desprezada. Talvez resultados mais expressivos possam ser obtidos em ensaios in vivo, uma vez que se considera que o processo de indução de resistência em plantas não é dose

Rev. Bras. PI. Med., Campinas, v.16, n.2, supl. I, p.309-315, 2014. 


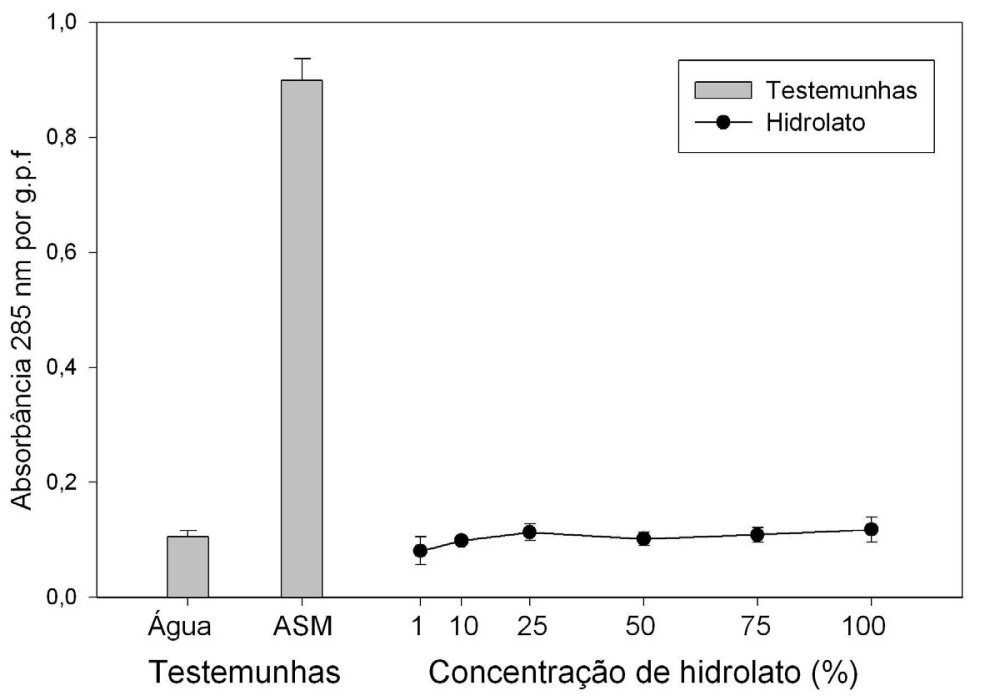

FIGURA 1. Produção de fitoalexinas em mesocótilos de sorgo em função do tratamento com diferentes concentrações do hidrolato de carqueja (em porcentagem), tendo como testemunhas água e acibenzolar-S-metil (ASM) (50 mg i.a. L-1). *Significativo a 5\% de probabilidade. g.p.f.: grama de peso fresco).

dependente.

Stangarlin et al. (1999), estudando o potencial de várias plantas medicinais em induzir a síntese de fitoalexinas, observaram que os extratos aquosos de romã (Punica granatum), erva cidreira (Lippia alba), manjerona (Origanum manjorana), babosa (Aloe vera) e orégano (Origanum vulgare) foram capazes de induzir fitoalexinas em sorgo e soja.

Embora sejam poucas as informações sobre o potencial indutor de fitoalexinas de hidrolato ou extrato de carqueja, considerável indução de fitoalexinas, a partir de extratos aquosos de outras plantas, tanto em sorgo como em soja já foram demonstrados, tais como: de Artemisia camphorata (Franzener et al., 2003) e de Eucaliptus citriodora (Bonaldo et al., 2004), com posterior comprovação in vivo.

\section{Atividade antibacteriana}

Foram obtidos resultados semelhantes para os três isolados bacterianos testados. Maior efeito antibacteriano foi promovido pelo antibiótico que reduziu em 93,4, 93,1 e 97,2\% a multiplicação bacteriana em relação ao meio caldo nutriente para $X$. campestris pv. campestris, E. carotovora e $B$. subtilis, respectivamente (Figura 2). Já o hidrolato promoveu significativa inibição da multiplicação bacteriana para os três isolados a partir da concentração $75 \%$, sendo que na concentração de $100 \%$ houve inibição de $65,3,32,5$ e $87,9 \%$ para $X$. campestris pv. campestris, $E$. carotovora e $B$. subtilis, respectivamente.
Avancini et al. (2000), avaliando a atividade do decocto de $B$. trimera sobre bactérias de interesse veterinário, relataram que em maior parte das combinações, de acordo com os resultados obtidos nesse trabalho, as bactérias Gram-positivas foram mais sensíveis ao decocto que as Gram-negativas, atribuindo efeito bactericida sobre algumas bactérias; porém, apenas em concentrações próximas a $100 \%$. Este efeito também é relatado por Oliveira et al. (2005) que avaliaram a atividade antibacteriana do extrato aquoso de diferentes espécies de Baccharis e verificaram maior atividade do extrato de $B$. trimera sobre a bactéria Gram-positiva Staphylococcus aureus. Esta informação confere com a obtida nesse trabalho onde a bactéria Gram-positiva $B$. subtilis foi a mais afetada. Assim, possivelmente compostos antimicrobianos da carqueja são mais efetivos sobre bactérias Gram-positivas do que Gram-negativas. Avancini et al. (2000) ainda citam que a presença de significativa atividade de derivados aquosos indica que suas substâncias antimicrobianas são também hidrossolúveis, justificando sua presença no hidrolato. Por outro lado, Duarte et al. (2007) avaliaram a atividade do óleo essencial de plantas medicinais sobre a bactéria Escherichia coli e observaram que o óleo de $B$. trimera apresentou atividade inferior à apresentada pelo óleo essencial de outras plantas como Cymbopogon martinii.

\section{Atividade antifúngica}

$O$ hidrolato de $B$. trimera, mesmo em maiores concentrações, não inibiu a germinação nem o desenvolvimento de tubos germinativos 

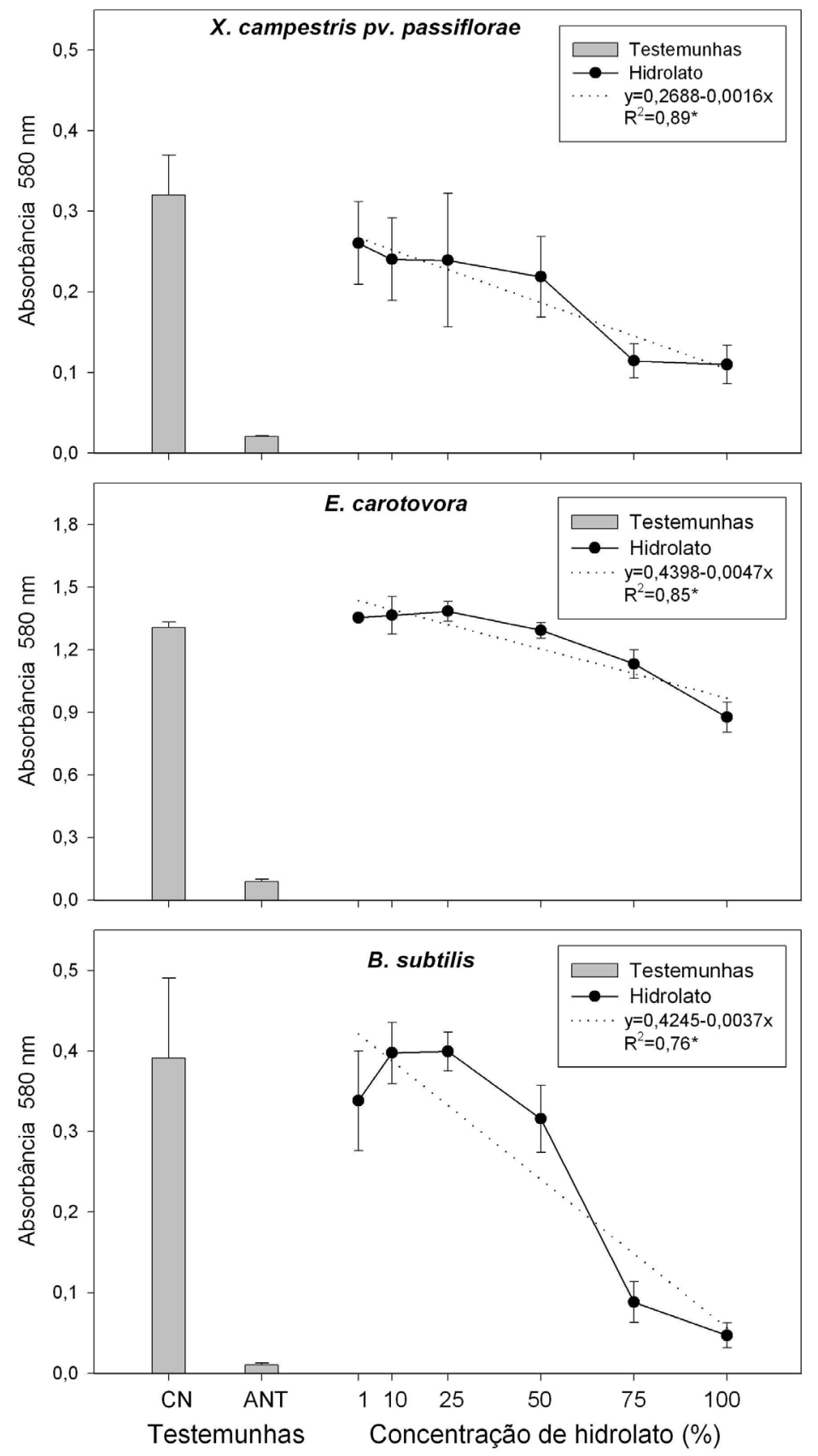

FIGURA 2. Multiplicação das bactérias Xanthomonas campestris pv. passiflorae, Erwinia carotovora e Bacillus subtilis em função do tratamento com diferentes concentrações do hidrolato de carqueja (em porcentagem), tendo como testemunhas o meio caldo nutriente (CN) e o antibiótico (ANT) $(22,5 \mathrm{mg} / \mathrm{L}$ de oxitetraciclina +225 $\mathrm{mg} / \mathrm{L}$ de estreptomicina). *Significativo a $5 \%$ de probabilidade.

dos três fungos avaliados. O único tratamento que afetou negativamente os fungos foi o fungicida que inibiu em 39, 29,9 e 97,4\% a porcentagem de germinação de esporos e em 58,9, 69,9 e 93,6\% o desenvolvimento de tubos germinativos, em relação a testemunha água, para $P$. vitis, C. kaki e $H$. vastatrix, respectivamente (Figura 3 ).

Os fungos $P$. vitis e C. kaki tiveram comportamento muito semelhante, pois além de se mostrarem insensíveis ao hidrolato, apresentaram significativo incremento no desenvolvimento de tubos germinativos em maiores concentrações do hidrolato. Na concentração de $100 \%$ os tubos germinativos foram 132,9 e $72,6 \%$ maiores do que em água, para $P$. vitis e C. kaki, respectivamente. Estes dados indicam a importância da avaliação 

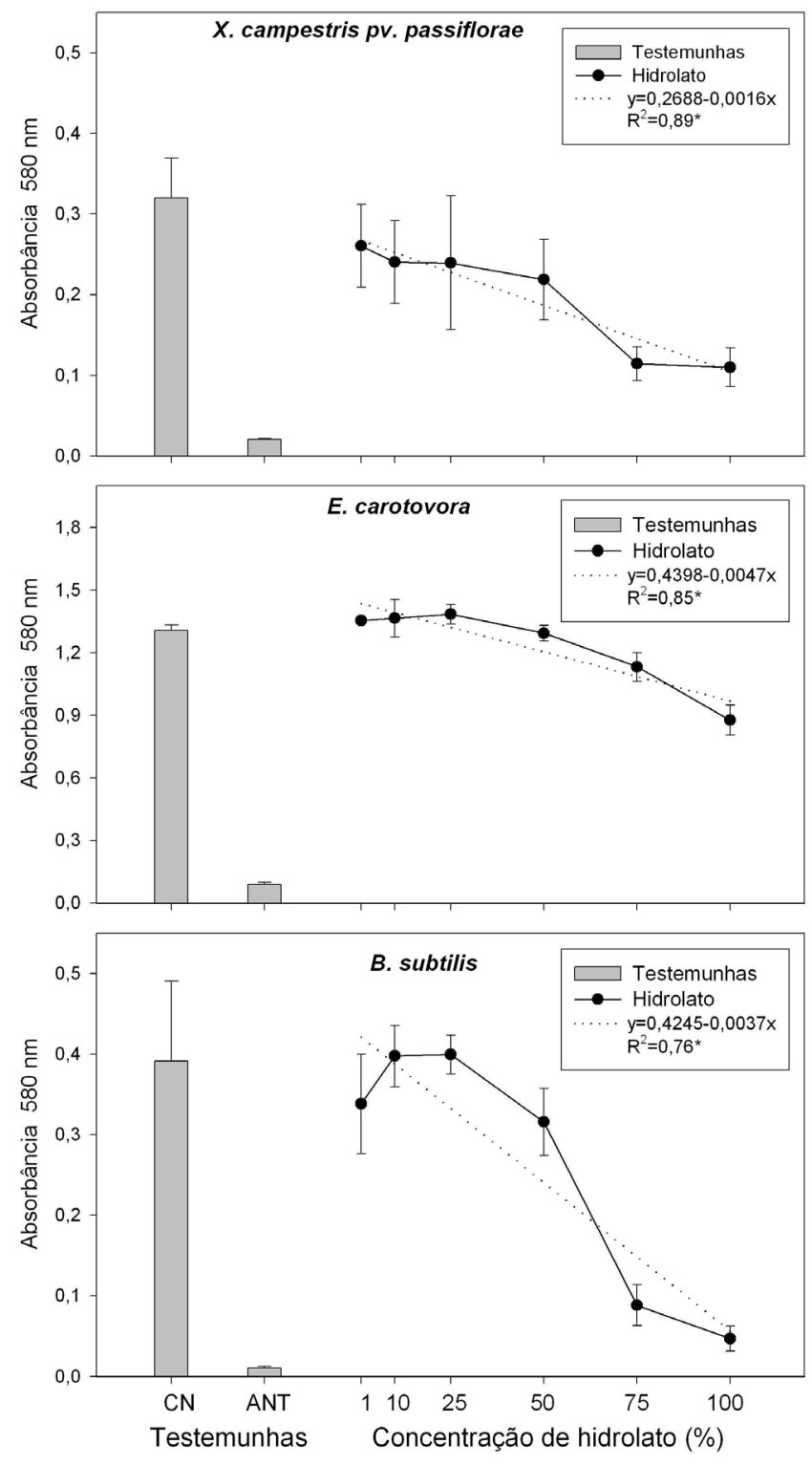

FIGURA 3. Porcentagem de germinação de esporos e tamanho de tubos germinativos de Pseudocercospora vitis (A), Cercospora kaki (B) e Hemileia vastatrix (C) em função do tratamento com diferentes concentrações do hidrolato de carqueja (em porcentagem), tendo como testemunhas água destilada e o fungicida azoxystrobin (0,08 g i.a./L) (FUN). *Significativo a $5 \%$ de probabilidade.

de tubos germinativos associada à porcentagem de germinação para melhor visualização dos resultados, sobretudo, para fungos com germinação mais uniforme. Em água, $H$. vastatrix apresentou porcentagem de germinação em torno de $20 \%$ menor em relação aos outros fungos; em compensação, teve crescimento mais rápido dos tubos germinativos.

O aumento no tamanho dos tubos germinativos (hifas) pode ser devido à presença de outras substâncias que podem ser utilizadas como nutrientes pelo patógeno (Franzener et al., 2003). Além disso, alguns fungos podem apresentar atividade de biotransformação de compostos presentes nas plantas, o que conduziria a inibição do efeito fungitóxico sobre os mesmos (Moreira, 2003). Contudo, possivelmente essa ausência de atividade é devido à ausência ou baixas concentrações de compostos antifúngicos no hidrolato de carqueja, pois para os três patógenos não houve atividade inibitória.

No entanto, esta atividade do hidrolato é dependente da espécie da planta da qual o mesmo é extraído, uma vez que Lozano et al. (2000) relatam maior atividade antifúngica para alguns hidrolatos e menor ou inexistente atividade para outros. Da mesma forma, Franzener et al. (2007) observaram efeito sobre Alternaria brassicae pelos hidrolatos de Helietta apiculata e Conyza canadensis, porém 
ausência de atividade pelo hidrolato de Cymbopogon nardus. Stangarlin et al. (1999), trabalhando com óleo essencial e extrato bruto de carqueja obtiveram inibição de $100 \%$ do crescimento micelial de vários fungos fitopatogênicos em placas de Petri contendo 500 e $1000 \mu \mathrm{L}$ de óleo, porém, apenas inibição parcial na presença do extrato bruto. Isto sugere que, possivelmente, compostos antifúngicos de carqueja tendem a se concentrar na fração apolar, como no óleo essencial, e pouco estará presente no hidrolato.

\section{CONCLUSÃO}

Os resultados obtidos indicam que o hidrolato de carqueja apresenta compostos ativos com potencial para o controle de doenças em plantas, principalmente por sua atividade antibacteriana, ou ainda, ativando a síntese de fitoalexinas.

\section{AGRADECIMENTOS}

Os autores agradecem a CAPES pelo concessão de bolsas de estudo e ao CNPq pela bolsa de produtividade em pesquisa.

\section{REFERÊNCIA}

AVANCINI, C.A.M. et al. Atividade bacteriostática e bactericida do decocto de Baccharis trimera (Less.) D.C., Compositae, carqueja, como desinfetante ou antiséptico. Arquivo Brasileiro de Medicina Veterinária e Zootecnia, v.52, n.3, p.230-234, 2000.

BONALDO, S.M. et al. Fungitoxidade, atividade elicitora de fitoalexinas e proteção de pepino contra Colletotrichum lagenarium, pelo extrato aquoso de Eucalyptus citriodora. Fitopatologia Brasileira, v.29, n.2, p.128134, 2004.

CAVALCANTI, L.S.; BRUNELLI, K.R.; STANGARLIN, J.R. Aspectos bioquímicos e moleculares da resistência induzida. In: CAVALCANTI, L.S. et al. (Eds). Indução de resistência em plantas a patógenos e insetos. Piracicaba:FEALQ. Cap.4. 2005. p.81-124.

DUARTE et al. Activity of essential oils from Brazilian medicinal plants on Escherichia coli. Journal of Ethnopharmacology, v.111, n.2, p.197-201, 2007.

FIORI, A.C.G. et al. Antifungal activity of leaf extracts and essential oils of some medicinal plants against Didymella bryoniae. Journal of Phytopathology, v.148, n.7/8, p.483-487, 2000.

FRANZENER, G. et al. Atividade antifúngica e indução de resistência em trigo a Bipolaris sorokiniana por Artemisia camphorata. Acta Scientiarum, v.25, n.2, p.503-507, 2003.

FRANZENER, G. et al. Atividades antibacteriana, antifúngica e indutora de fitoalexinas de hidrolatos de plantas medicinais. Semina: Ciências Agrárias, v. 28, n.1, p.29-38, 2007.

GHINI, R.; KIMATI, H. Resistência de fungos a fungicidas. Jaguariúna, SP: Embrapa Meio Ambiente, 2000. 78p.

KAGALE, S. et al. Antimicrobial activity and induction of systemic resistance in rice by leaf extract of Datura metel against Rhizoctonia solani and Xanthomonas oryzae pv. oryzae. Physiological and Molecular Plant Pathology, v.65, n.2, p.91-100, 2004.

LAVABRE, M. Aromaterapia: a cura pelos óleos essenciais. Rio de Janeiro: Record. 1993. 172p.

LORENZI, H.; MATOS, F.J.A. Plantas medicinais no Brasil: nativas e exóticas. Nova Odessa: Instituto Plantarum, 2002. 512p.

LOZANO, C. et al. Evaluacion del efecto de hidrolatos de ajo (Allium sativum) y cebolla junca (Allium fistulosum) en el desarollo de los hongos fitopatogenos Botrytis alli y Sclerotium cepivorum. Fitopatologia Colombiana, v.24, n.1, p.29-32, 2000.

MOREIRA, C.G.A. Caracterização parcial de frações eliciadoras presentes em extratos de Cymbopogon nardus. 2003. 51p. Dissertação (Mestrado em Agronomia) - Universidade Estadual de Maringá, Maringá.

MOTOYAMA, M.M. et al. Efeito antimicrobiano de extrato cítrico sobre Ralstonia solanacearum e Xanthomonas axonopodis pv. manihotis. Acta Scientiarum, v.25, n.2, p.509-512, 2003.

NICHOLSON, R.L. et al. Phytoalexin synthesis in the juvenile sorghum leaf. Physiological and Molecular Plant Pathology, v.33, n.2, p.271-278, 1988.

OLIVEIRA et al. Screening of antibacterial activity of South Brazilian Baccharis species Pharmaceutical Biology, v.43, n.5, p.434-438, 2005.

REGENTE, M.C. et al. Sunflower leaf antifungal peptide active against Sclerotinia sclerotiorum. Physiologia Plantarum, v.100, n.1, p.178-182, 1997.

RÍOS, J.L.; RECIO, M.C. Medicinal plants and antimicrobial activity. Journal of Ethnopharmacology, v.100, n.1/2, p.80-84, 2005.

SCHWAN-ESTRADA, K.R.F.; STANGARLIN, J.R. Extratos e óleos essenciais de plantas medicinais na indução de resistência. In: CAVALCANTI, L.S. et al. (Eds). Indução de resistência em plantas a patógenos e insetos. Piracicaba:FEALQ. Cap.5. 2005. p.125-138.

STANGARLIN, J.R. et al. Plantas medicinais e controle alternativo de fitopatógenos. Biotecnologia Ciência \& Desenvolvimento, v.2, n.11, p.16-21,1999.

STANGARLIN, J.R.;KUHN, O.J.; SCHWAN-ESTRADA, K.R.F. Controle de doenças de plantas por extratos de origem vegetal. Revisão Anual de Patologia de Plantas, v.16, p.265-304, 2008.

TESKE, M.; TRENTINI, A.M.M. Herbarium - Compêndio de Fitoterapia. Curitiba: Herbarium, 1997, 317p.

ZIEGLER, E.; PONTZEN, R. Specific inhibition of glucanelicited glyceolin accumulation in soybeans by na extracellular mannan-glycoprotein of Phytophthora megasperma f.sp. glycinea. Physiological Plant Pathology, v. 20, p. 321-331, 1982. 